\title{
Localized rbp4 expression in the yolk syncytial layer plays a role in yolk cell extension and early liver development Zhen $\mathrm{Li}^{1,3}$, Vladimir Korzh*1,2 and Zhiyuan Gong*1,3
}

\author{
Address: ${ }^{1}$ Department of Biological Sciences, National University of Singapore, Singapore, ${ }^{2}$ Laboratory of Fish Developmental Biology, Institute \\ of Molecular and Cell Biology, Singapore and ${ }^{3}$ Computation and System Biology Program, Singapore-MIT Alliance, National University of \\ Singapore, Singapore \\ Email: Zhen Li - g0203805@nus.edu.sg; Vladimir Korzh* - vlad@imcb.a-star.edu.sg; Zhiyuan Gong* - dbsgzy@nus.edu.sg \\ * Corresponding authors
}

Published: 19 October 2007

BMC Developmental Biology 2007, 7:1 17 doi:10.1186/1471-213X-7-117

This article is available from: http://www.biomedcentral.com/I47I-2I3X/7/II7

(C) $2007 \mathrm{Li}$ et al; licensee BioMed Central Ltd.

This is an Open Access article distributed under the terms of the Creative Commons Attribution License (http://creativecommons.org/licenses/by/2.0), which permits unrestricted use, distribution, and reproduction in any medium, provided the original work is properly cited.
Received: 23 March 2007

Accepted: 19 October 2007

\begin{abstract}
Background: The number of genes characterized in liver development is steadily increasing, but the origin of liver precursor cells and the molecular control of liver formation remain poorly understood. Existing theories about formation of zebrafish visceral organs emphasize either their budding from the endodermal rod or formation of independent anlage followed by their later fusion, but none of these is completely satisfactory in explaining liver organogenesis in zebrafish.

Results: Expression of a gene encoding the retinol binding protein 4 (Rbp4) was analyzed in zebrafish. rbp4, which is expressed mainly in the liver in adults, was shown to be expressed in the yolk syncytial layer (YSL) during early embryogenesis. At 12-16 hpf rbp4 expression was restricted to the ventro-lateral YSL and later expanded to cover the posterior YSL. We demonstrated that rbp4 expression was negatively regulated by Nodal and Hedgehog $(\mathrm{Hh})$ signalling and positively controlled by retinoic acid (RA). Knockdown of Rbp4 in the YSL resulted in shortened yolk extension as well as the formation of two liver buds, which could be due to impaired migration of liver progenitor cells. rbp4 appears also to regulate the extracellular matrix protein Fibronectin I (FnI) specifically in the ventro-lateral yolk, indicating a role of $\mathrm{FnI}$ in liver progenitor migration. Since exocrine pancreas, endocrine pancreas, intestine and heart developed normally in Rbp4 morphants, we suggest that rbp4 expression in the YSL is required only for liver development.
\end{abstract}

Conclusion: The characteristic expression pattern of rbp4 suggests that the YSL is patterned despite its syncytial nature. YSL-expressed Rbp4 plays a role in formation of both yolk extension and liver bud, the latter may also require migration of liver progenitor cells.

\section{Background}

The YSL is an extra-embryonic structure and it forms at the stage of mid-blastula transition (MBT) in teleosts $[1,2]$ by a poorly understood developmental mechanism. The YSL performs several early developmental functions such as yolk metabolism, nutrient transport [3], utilization of maternally stored morphogenetic substances including retinoids [4,5], and epiboly movement [6]. It also plays a morphogenetic role during gastrulation in induction and patterning of mesoderm, endoderm and dorsal structures [7-13]. However, there is little information on the function of the YSL after epiboly is completed. Recently it has been reported that the YSL-specific factor Mtx1 plays a role in migration of myocardial precursor cells and knock- 
down of Mtx1 in the YSL resulted in cardia bifida and duplication of liver and pancreatic buds. Based on these results it has been proposed that the YSL regulates migration of endodermal cells [14].

Rbp4 is produced in the adult liver and functions as a specific transporter of retinol in vertebrate plasma. Expression of $r b p 4$ has been studied in several model animals. During embryonic development of rodents it is expressed only in the visceral extra-embryonic endoderm of the yolk sac, suggesting that Rbp4 may play roles in mediating retinol transfer from maternal blood to the developing fetus $[15,16]$. Similar expression has also been reported in chick [17]. In zebrafish, rbp4 has been reported to be expressed in the YSL, hypochord and skin [18]. It is of interest to analyse the role of rbp4 in zebrafish development.

The liver is an important endodermal organ, which exerts both endocrine and exocrine functions. Many studies have revealed that the molecular mechanisms of liver development are conserved in vertebrates [19-21]. Furthermore, cell fate mapping experiments in zebrafish, frog and mouse have also indicated that the liver arises, at least in part, from different groups of endodermal cells found initially in bilateral regions on both sides of the midline [22-24]. Despite this progress the mechanism of liver bud formation in zebrafish is not fully understood. According to one hypothesis based to a large extent on observations of gutGFP transgenic zebrafish, the early endoderm forms as an endodermal rod, which starts to bud and gives rise to several primordia including the liver primordium which grows mainly due to cell proliferation within the primordium $[25,26]$. A conflicting view based on analysis of different molecular markers implies that whereas the digestive anlagen of amniotes arise from a primitive gut tube, the zebrafish digestive system is assembled from individual organ anlage [27]. In addition, based on analysis of the expression pattern of ceruloplasmin in wild type and mutant zebrafish, migration of progenitor cells from posterior to anterior and towards the midline has been proposed to take place during formation of the liver [28]. Recently, this hypothesis has been supported by discovery of the posterior-to-anterior migration of cells between the enveloping layer (EVL) and YSL, which is linked to the formation of the yolk cell extension (YCE; [29]).

In this study, we demonstrated that early expression of $r b p 4$ in the YSL is restricted only to the ventro-lateral YSL. rbp4 expression is negatively controlled by Nodal and $\mathrm{Hh}$ signalling pathways and positively regulated by RA. The YSL-specific knockdown of Rbp4 caused inhibition of the YCE formation and formation of two liver buds. Thus, Rbp4 probably plays a role in morphogenesis of the yolk cell and formation of the liver bud.

\section{Results \\ Expression of rbp4 mRNAs}

The EST clone coding for Rbp4 (A 10) from our collection [30] was selected and sequenced completely. The complete sequence was submitted to GenBank (acc. no. EF373650) and it was almost identical (99.5\%) to a sequence previously available (GenBank AJ236884, [18]). To investigate the temporal expression pattern of rbp4 in early development, rbp4 transcripts were analyzed by RTPCR from fertilized eggs to $14 \mathrm{hpf}$. We found that rbp4 transcripts were of maternal origin and the zygotic expression of rbp4 increased from 6 hpf to reach its peak by 12 hpf (Figure 1A).

To further investigate the pattern of $r b p 4$ expression in zebrafish embryos, whole mount in situ hybridization (WISH) was carried out. Transcripts of rbp4 were detected from $12 \mathrm{hpf}$ on the yolk surface anterior to the head. This expression domain was confined to the ventro-lateral yolk cell (Figure 1B, C). At $16 \mathrm{hpf}, \mathrm{rbp} 4$ expression increased and expanded posteriorly but remained confined to the ventro-lateral yolk cell (Figure 1D). To define this expression domain in detail, two-colour WISH using ctsL (cathe$p \sin L$, [31]) and $r b p 4$ probes was performed at $16 \mathrm{hpf}$. ctsL was expressed in the hatching gland mesoderm around the head as expected, while the anterior end of the rbp4 expression domain was found to spread under the head (Figure 1D). A cross section indicated that $c t s L$ and $r b p 4$ were expressed in different layers of tissue (Figure 1E, G). DAPI staining clearly revealed that the enlarged nuclei, characteristic of the YSL, were surrounded by rbp4 transcripts (Figure 1F, F'), while the superficial cellular layer or the enveloping layer was free of $r b p 4$ transcripts. Thus, the expression of $r b p 4$ on the surface of the yolk cell was probably confined to the YSL. To the best of our knowledge this is the first molecular marker of the ventro-lateral YSL.

At $24 \mathrm{hpf}$, rbp4 expression in the YSL is restricted to its posterior part including that in the YCE (Figure 2A). This expression pattern remained unchanged at least until 48 hpf (Figure 2B). Later the expression spread anteriorly but remained excluded from the pericardium (Figure 2C). By $4 \mathrm{dpf}, \mathrm{rbp} 4$ expression was detected in the liver (Figure 2C). By 8 dpf the liver became the only tissue with detectable rbp4 expression (Figure 2D).

To understand the developmental mechanism controlling the unusual spatial expression pattern of $r b p 4$ in the YSL, the expression pattern of this gene in several mutants affecting various aspects of early endoderm development was analyzed. In mutants affecting Nodal signalling ( $c y c$ and oep) (Figure 2E, F), rbp4 expression expanded anteriorly and covered the whole yolk. Similar changes of expression pattern were also observed in mutants that affected components of the Hh signalling pathway, smu 


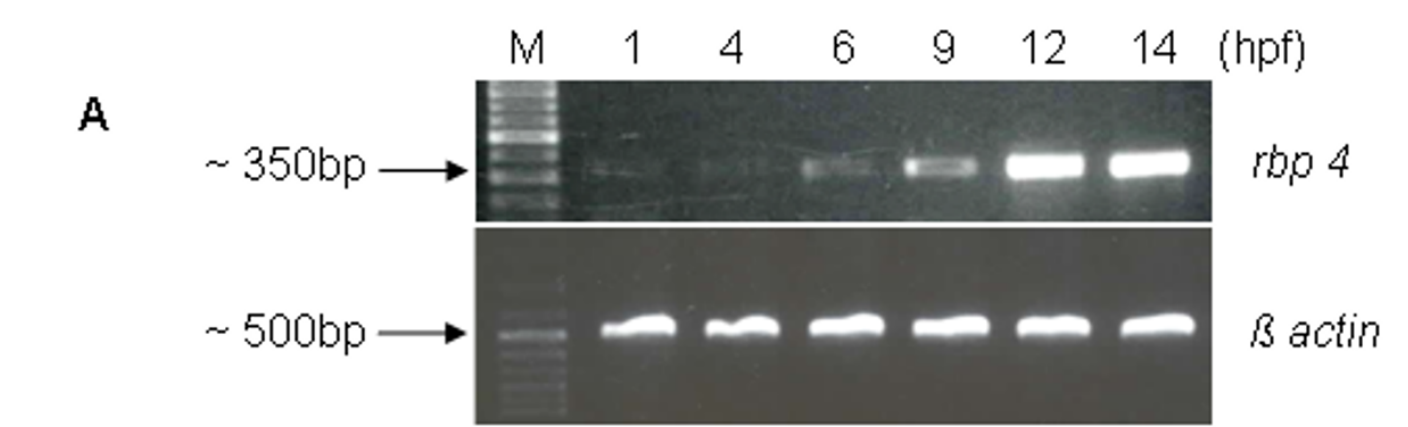

\begin{tabular}{|llllll|}
\hline rbp4 $12 \mathrm{hpf}$ ventral rbp4 $12 \mathrm{hpf}$ lateral rbp4/ctsL $16 \mathrm{hpf}$ ventral \\
\hline
\end{tabular}
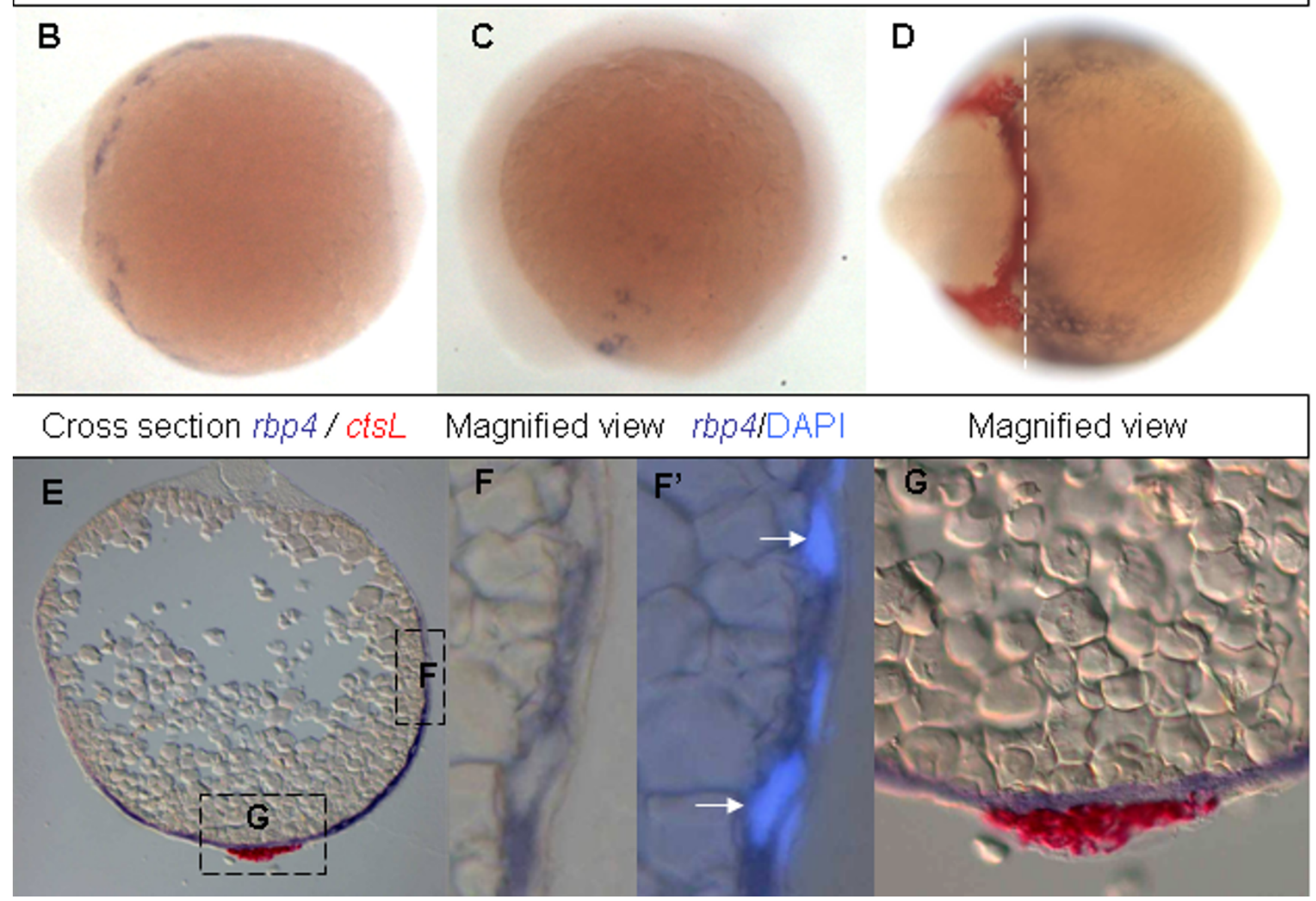

\section{Figure I}

Expression of rbp4 mRNA during early zebrafish embryogenesis. (A) RT-PCR analysis of rbp4 mRNA in wild-type embryos from I hpf to I4 hpf. $\beta$-actin was used as loading control. M, I00 bp DNA marker. (B, C) Ventral (B) and lateral (C) view of 12 hpf embryos with rbp4 expression as detected by WISH. (D) Ventral view of 16 hpf embryos with expression of ctsL (red) and rbp4 (blue) as detected by two-colour WISH. (E) Cross section of the two color hybridized embyos in (D) as indicated by the dashed line. (F, F') Magnified view of boxed region $F$ in Panel (E). F, bright field. F', compound image of DIC/fluorescence reveals rbp4 expression and position of nuclei detected by DAPI staining. Arrows indicate YSL nuclei. (G), Magnified view of boxed region $G$ in Panel $(E)$. 


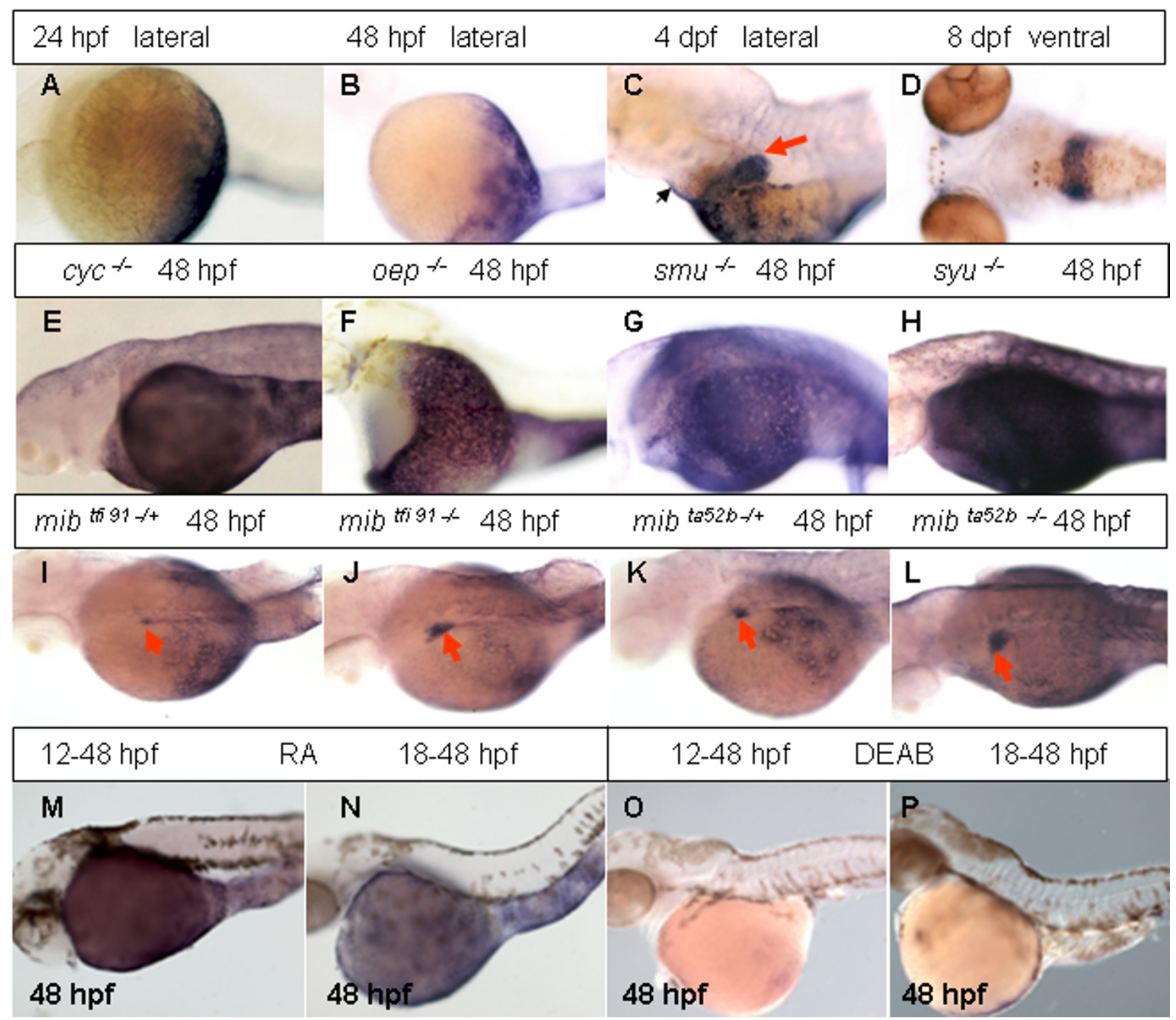

Figure 2

Analyses of rbp4 expression during late development and its regulation. (A-D) rbp4 expression in $24 \mathrm{hpf}, 48 \mathrm{hpf}, 4$ $\mathrm{dpf}$ and $8 \mathrm{dpf}$ wild-type embryos as indicated. A red arrow indicates the liver while a black arrow indicates the pericardium

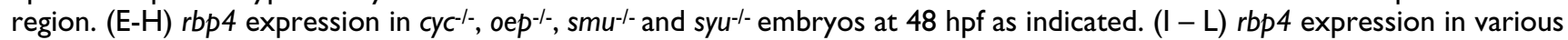
heterozygous and homozygous mib mutant embryos as indicated. Red arrows indicate the liver. Note precocious appearance of rbp4 expression in homozygous mutant liver at $48 \mathrm{hpf}(\mathrm{J}, \mathrm{L})$ compared to heterozygous mib embryos (I, K). (M, N) rbp4 expression in $48 \mathrm{hpf}$ embryos treated with 10-6 M RA initiated from $12 \mathrm{hpf}(\mathrm{M})$ or $18 \mathrm{hpf}(\mathrm{N})$. (O, P) rbp4 expression in $48 \mathrm{hpf}$ embryos treated with $10^{-5}$ M DEAB initiated from $12 \mathrm{hpf}(\mathrm{O})$ and $18 \mathrm{hpf}(\mathrm{P})$.

(Figure 2G), syu (Figure 2H) and yot (not shown). As the restricted expression pattern of $r b p 4$ was lost at $48 \mathrm{hpf}$ in these mutants, it is likely that the early expression pattern of $r b p 4$ in the YSL is under negative regulation of the Nodal and Hedgehog signaling pathways, which prevent the rbp4 expression in the anterior and dorsal YSL.
In the mibtfig1 mutant which has a nonsense mutation in the gene encoding E3 ubiquitin ligase involved in ubiqutination of Delta, a ligand of Notch signaling, Delta is upregulated causing premature differentiation of neural progenitor cells [32]. The restricted $r b p 4$ expression pattern in the YSL was maintained, but the expression in the liver 
appeared much earlier than that in control embryos (48 hpf vs. $96 \mathrm{hpf}$ ). In addition, the rbp4 expression in the

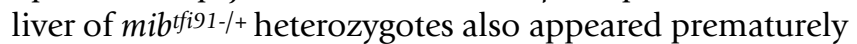
but the expression domain was smaller than that in mibtivi- homozygotes (Figure 2I and 2J). Further analysis of another allele of mib mutant, mibta52b, demonstrated that the expression domain of $r b p 4$ in the liver is larger in the mib ta52b allele (Figure $2 \mathrm{~K}$ and $2 \mathrm{~L}$ ) than that in the mibtivi allele. This is in accordance with the fact that mibta52b-/- allele is a stronger dominant negative mutation, while the mibtiis $\%$ - allele is a weaker null allele [32].

Analyses of embryos of two mutant lines with defects in formation of axial mesoderm, spt and $n t l$, did not show obvious changes in expression pattern of $r b p 4$ from $16 \mathrm{hpf}$ to $24 \mathrm{hpf}$, suggesting that the formation of axial mesoderm probably does not influence events involving rbp4 in the YSL (not shown).

\section{RA positively regulates rbp4 expression in the YSL}

Retinol is the precursor of RA, which plays important roles in many aspects of development $[33,34]$. In order to examine whether RA could regulate rbp4 expression, different doses of RA and DEAB (4-diethylaminobenzaldehyde), an inhibitor of RA synthesis acting through inhibition of retinaldehyde dehydrogenase [35], were applied to wild type embryos starting from $12 \mathrm{hpf}, 16 \mathrm{hpf}$ and $18 \mathrm{hpf}$, respectively. Control embryos were soaked in $0.1 \% \mathrm{DMSO} /$ egg water. WISH on $48 \mathrm{hpf}$ embryos with the rbp4 probe showed that in all cases RA treatment caused expansion of $r b p 4$ expression (Figure $2 \mathrm{M}$ and $2 \mathrm{~N}$ ). In contrast, DEAB treatment caused reduction of $r b p 4$ expression (Figure $2 \mathrm{O}$ and $2 \mathrm{P}$ ). Thus, RA positively regulates $r b p 4$ expression in the YSL. It is interesting to note that the phenotypes were more severe when the treatment was initiated early. In the RA treatment group, rbp4 expression was generally stronger in embryos treated from 12 hpf (Figure 2M) than that from $18 \mathrm{hpf}$ (Figure 2N). In the DEAB treatment group, the yolk extension was affected more severely when the treatment was started from $12 \mathrm{hpf}$ than from $18 \mathrm{hpf}$. The embryos treated from $12 \mathrm{hpf}$ showed no yolk extension (Figure 2O) or a very short one, whereas the embryos treated from 18 hpf showed only mild shortening of the yolk extension (Figure 2P).

\section{Functional analysis of Rbp4 in zebrafish by morpholino knockdown}

To study the role of rbp4 during early development, the morpholino knockdown technique was employed $[36,37]$. Since the initial expression of $r b p 4$ occurs in the YSL, we first focused on a role of this gene in this structure. For this purpose we used the YSL-targeted injection of anti-Rbp4 morpholino ( $\mathrm{MO}$ ) (see Methods for details). Two anti-Rbp4 MOs were designed, one for translation blocking by targeting the 5'-ATG area (ATG-MO) and the other to block splicing by targeting the junction of the $2^{\text {nd }}$ exon and $2^{\text {nd }}$ intron (Spl-MO). After injection of the ATG$\mathrm{MO}$, the morphants developed relatively normally at least until 16 hpf, but approximately $20 \%$ of injected embryos developed a shorter YCE and much larger yolk cell (Table 1). Furthermore, the whole yolk cell of morphants became abnormally dark at 4-5 dpf and they died soon after. Injection of Spl-MO generated morphants with this phenotype more efficiently and in a dose-dependant manner (Table 1). At a low dose $(0.4 \mathrm{pmol})$, the YCE in $58.3 \%$ of morphants was shorter than that in controls. At a medium dose $(0.8 \mathrm{pmol}), 87.3 \%$ of morphants displayed abnormal YCE: $77.1 \%$ featured short YCE and $10.2 \%$ lacked it completely (Figure 3B, C, E and 3F). At a high dose (1.3 pmol), $93.5 \%$ of morphants were affected and the fraction lacking YCE increased to $27.3 \%$. To verify the specificity of Spl-MO, a 5 nucleotide mismatched morpholino (Mis-MO) was also synthesized and tested, and there was no noticeable change in the YCE (Table 1).

RT-PCR was used to validate the specificity of Spl-MO. Two sets of primers were designed to monitor the splicing of $r b p 4$ transcript: F1 (spanning the junction of exons 2 and 3) + R1 (targeting the $5^{\text {th }}$ exon); F2 (targeting the $2^{\text {nd }}$ intron)+R1 (Figure 3G). When PCR extension time was set at 0.5 minute, F2 $+\mathrm{R} 1$ would only amplify the unspliced transcripts and no genomic DNA would be amplified due to presence of the large $4^{\text {th }}$ intron $(3 \mathrm{~kb})$. Similarly, primers $\mathrm{F} 1+\mathrm{R} 1$ would amplify only the correctly spliced rbp4 transcripts but not genomic DNA or unspliced rbp 4 template. As shown in Figure 3H, correctly spliced $r b p 4$ transcripts were reduced and the unspliced transcripts were present in $24 \mathrm{hpf}$ morphants (Figure $3 \mathrm{H}$ ). Sequence analysis also confirmed that the PCR fragment contained the unspliced intron (not shown). Protein

Table I: Morphological phenotype of rbp4 morphants

\begin{tabular}{ccccc}
\hline PhenotypelMO & Total & Type I (no YCE) & Type II (short YCE) & Normal \\
\hline ATG MO (0.8 pm) & 125 & $0.0 \%$ & $20.0 \%$ & $80.0 \%$ \\
Spl MO (0.4 pm) & 48 & $0.0 \%$ & $58.3 \%$ & $41.7 \%$ \\
Spl MO (0.8 pm) & 166 & $10.2 \%$ & $77.1 \%$ & $12.7 \%$ \\
Spl MO (I.3 pm) & 77 & $27.3 \%$ & $66.2 \%$ & $6.5 \%$ \\
Mis-MO(0.8 pm) & 65 & $0.0 \%$ & $0.0 \%$ & $100.0 \%$ \\
\end{tabular}



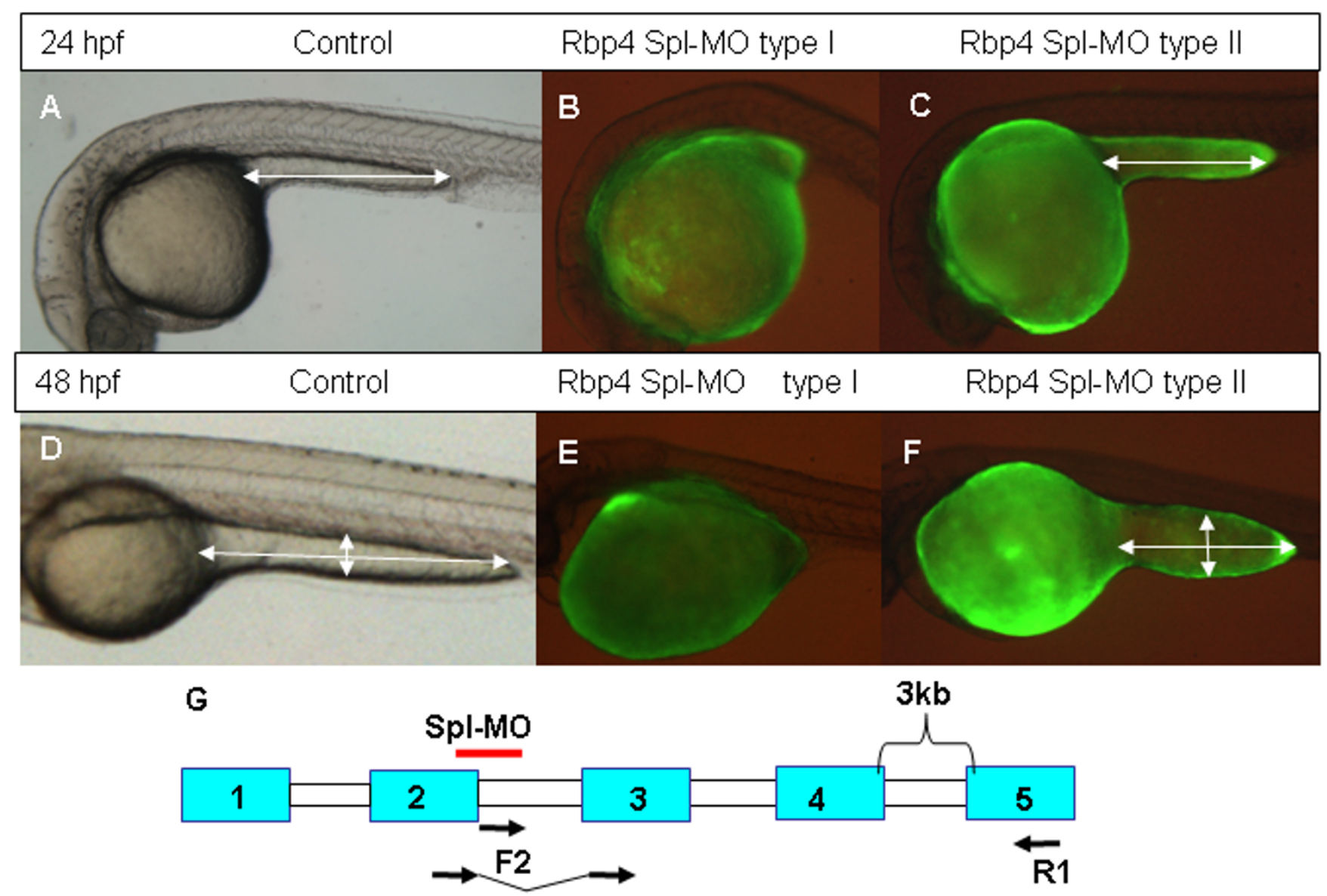

H

F1

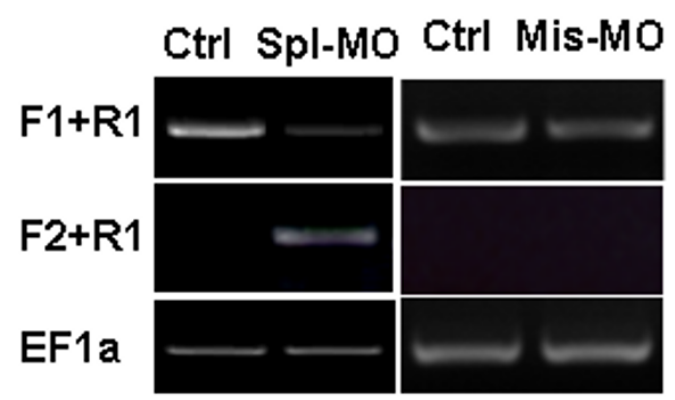

Figure 3

Effects of Rbp4 splicing MO on morphology of embryos. Rbp4 Spl-MO was injected into the blastoderm margin area at $4 \mathrm{hpf}$ with Fluorescein and injected embryos were photographed at 24 hpf and 48 hpf. (A, D) Control embryos at 24 hpf and 48 hpf. (B, E) Fluorescent lateral view image of type I phenotype (without yolk cell extension) morphants at $24 \mathrm{hpf}(\mathrm{B})$ and $48 \mathrm{hpf}$ (E). (C, F) fluorescent lateral view image of type Il phenotype (short yolk cell extension) morphants at $24 \mathrm{hpf}(\mathrm{C})$ and $48 \mathrm{hpf}$ (F). White double arrows indicate the length and width of yolk extension. (G) Scheme of splicing morpholino and RT-PCR primer positions in the rbp4 gene. Exons are represented by blue boxes with numbers and introns by white boxes. A red bar indicates the region targeted by Rbp4 Spl-MO. (H) RT-PCR analysis of RNAs from control (Ctrl) (non-injection)/splcing morphlino injected embryos (Spl-MO) and control (Ctrl) (non-injection)/mismatch morpholino injected embryos (Mis-MO) at 24 hpf using the rbp4 primers as indicated in Panel (G) or EFI a control primers. 
sequence prediction from the unspliced transcript showed a premature stop codon after 10 amino acid residues. As a result, the unspliced transcript encoded only the signal peptide. Furthermore, RT-PCR was performed on $24 \mathrm{hpf}$ uninjected control and Mis-MO injected embryos using the same pairs of primers as for the Spl-MO. As shown in Fig $3 \mathrm{H}$, the level of correctly spliced $r b p 4$ transcripts in the Mis-MO injected embryos was similar to that of control while unspliced transcripts were not detectable in the Mis$\mathrm{MO}$ injected embryos. Thus, these experimental data demonstrated that the anti-Rbp4 Spl-MO efficiently blocked the processing of $r b p 4$ mRNA.

\section{Liver development in Rbp4 morphants}

To study the developmental changes in the morphants, several markers expressed in the YSL and endodermal organs were employed. The liver marker transferrin [38] indicated two liver buds on both sides of the body axis in embryos injected with either ATG-MO or Spl-MO injection, but not in Mis-MO injected embryos (Table 2). Compared with $27.6 \%$ of ATG-MO morphants with two liver buds, a much higher percentage $(72.1 \%)$ of Spl-MO morphants showed this phenotype (Table 2). The two liver buds were either connected with each other or separated (Figure 4A-D). This phenotype also appeared in a dose-dependant manner; the high dose of Spl-MO caused an increase in a number of morphants with separated liver buds (data not shown). Duplication of liver or other unpaired visceral organs such as pancreas, heart and interrenal gland have been previously observed in mutants with defective midline formation [14,39-41]. In order to examine whether the phenomenon of duplicated liver in Rbp4 morphants was also due to midline defects, several midline markers were evaluated in the morphants at 18 and 24 hpf. shh (Figure 4G, H), no tail and twh were expressed normally suggesting that formation of the notochord and floor plate was not affected. Therefore the duplication of the liver bud in Rbp4 morphants is not related to defects in midline formation. To further analyze liver morphology, cross-section of 48 hpf morphants was performed. From anterior to posterior, the two liver buds contain several layers of cells similar to that in control (Figure 4E, F). Thus it seems that the two liver buds undergo at least initial stages of hepatogenesis. At the same time, these sections also showed that the gut was normal. In contrast to the YSL-injection, injection of morpholino at 1-cell stage resulted in a lower percentage of the duplicated liver phenotype $(5.8 \%, \mathrm{n}=52)$. In addition, defects in the brain and tail were observed (data not shown), indicating Rbp4 may have other functions during development. While this study focused on a role of Rbp4 during liver development, other functions of Rbp4 will be analyzed in future.

To analyze development of pancreas, the Tg(ins:gfp) that expresses GFP in insulin-producing endocrine pancreatic cells [42] as well as molecular markers for the exocrine (elastaseA or elaA) and endocrine (somatostatin2 or sst2) pancreas were used. In both Rbp4 morphants and controls, GFP-positive endocrine $\beta$-cells were found on the right side of the midline (Figure 4I, J). Similarly, the sst2positive endocrine cells and elaA-positive exocrine cells were found in the same position (Figure $4 \mathrm{~K}-\mathrm{N}$ ). Thus, Rbp4 knockdown causes duplication of the liver but not the pancreas. This suggests that Rbp4 probably plays a role only in early liver development. In addition, we never noticed heart duplication in Rbp4 morphants; this observation was further supported by the fact that the expression of gata6, an early endoderm and heart marker [43], was not affected at $28 \mathrm{hpf}$ (data not shown).

Migration of endodermal cells towards the midline has been implicated in formation of several visceral organs, including the liver, pancreas, interrenal gland and heart $[28,41,14]$. Therefore several early endodermal markers were analyzed in morphants. Among these, foxa3 is a panendodermal marker and is expressed in several endodermal organs including the liver during pharyngula period [44]. As shown in Figure 5D compared to Figure 5A control, there was no altered foxa 3 expression in Rbp4 morphants at $11 \mathrm{hpf}$, indicating that the early convergence of anterior endoderm was not affected by knockdown of $\mathrm{Rbp} 4$. However, at $16 \mathrm{hpf}$ when there was a major increase of $r b p 4$ mRNA in the YSL, in addition to its normal expression in the hatching gland and tail bud [44], foxa 3 expression in the morphant was observed on the ventro-lateral yolk surface in the morphant (Figure $5 \mathrm{E}$ ) but not in the control embryos (Figure 5B). Interestingly, this ectopic foxa3 expression was detected mainly anteriorly. At later stage, duplicated expression domains in the liver bud regions were observed in the morphant (Figure 5F) but not in the control (Figure 5C). The YSL and lateral plate mesodermal marker hhex [45-47] was also used in the study, but there was no obvious alteration of its expres-

Table 2: Evaluation of rbp4 morphants by transferrin expression

\begin{tabular}{ccccc}
\hline PhenotypelMO & Total & Two-sided & No-expression & Left-sided \\
\hline ATGMO $(0.8 \mathrm{pm})$ & 58 & $27.6 \%$ & $0.0 \%$ & $72.4 \%$ \\
SpI MO (0.8 pm) & 122 & $72.1 \%$ & $7.4 \%$ & $20.5 \%$ \\
Mis-MO $(0.8 \mathrm{pm})$ & 16 & $0.0 \%$ & $0.0 \%$ & $100.0 \%$ \\
\hline
\end{tabular}




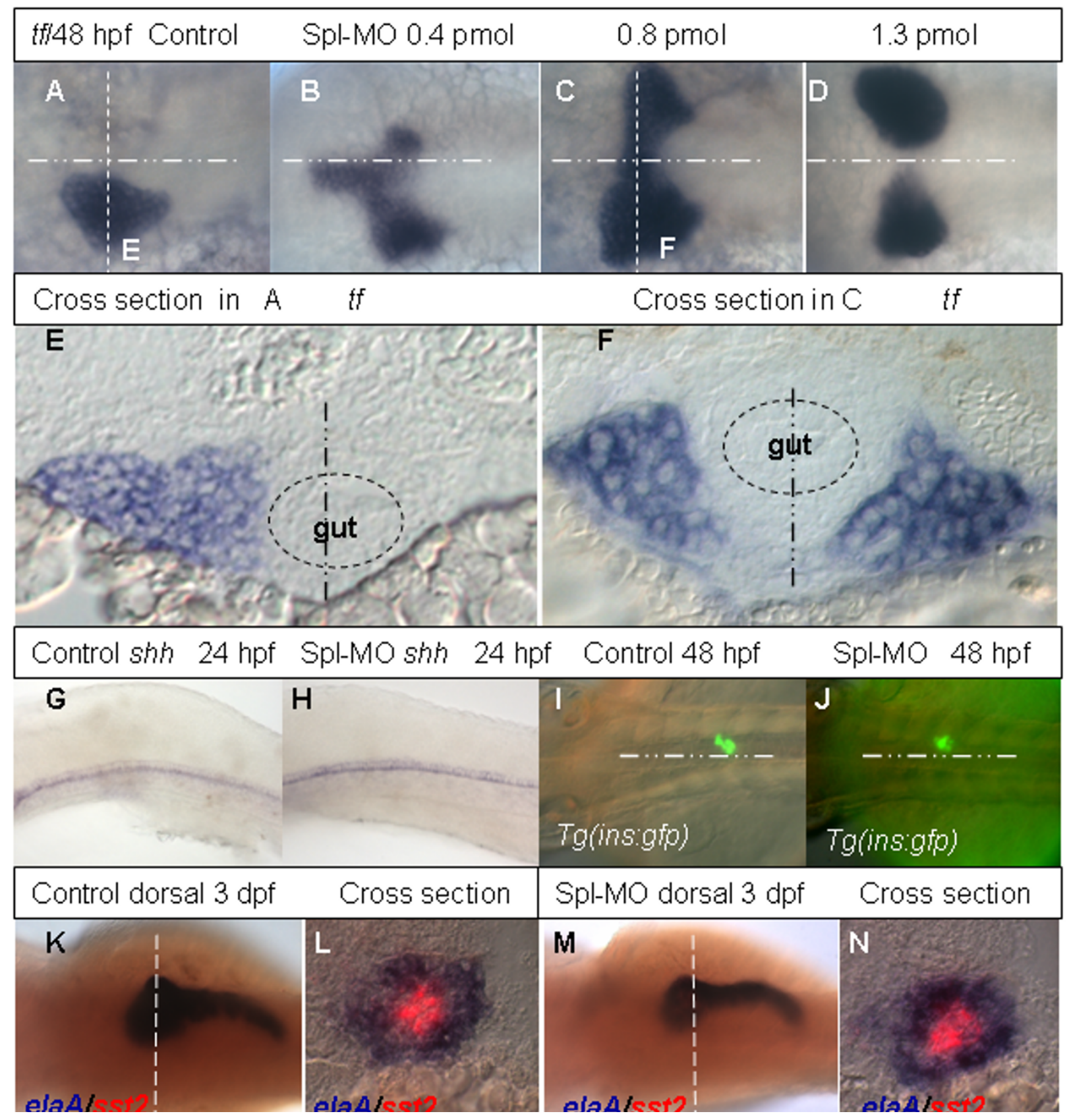

\section{Figure 4}

Analyses of liver and pancreas development in Rbp4 morphants. (A-D) Dorsal view of transferrin expression at 48 hpf in a control embryo (A) and in $48 \mathrm{hpf}$ embryos injected with increasing dosage of Spl MO as indicated (B-D). The midline is indicated by a horizontal point/dash line. (E, F) Cross sections of the control embryo in (A) and morphant in (C) respectively. The section plane is indicated in $(A, C)$ by the vertical dash line. Dashed circles in $(E, F)$ represent gut and the vertical poin/dash lines indicate the midline. $(\mathrm{G}, \mathrm{H})$ Lateral view of shh expression in 24 hpf control embryo $(\mathrm{G})$ and morphant $(\mathrm{H})$. (I, J) Dorsal view of GFP expression in the principle islet of pancreas in 48 hpf control Tg(ins:gfp) embryo (I) and morphant (J). (K-N) Control and morphant stained using two-color WISH with fluorescein-labeled somatostatin 2(red) and Dig-labeled elaA (blue). Panels $(\mathrm{K}, \mathrm{M})$ shows dorsal views of $3 \mathrm{dpf}$ control and morphant respectively. Panels $(\mathrm{L}, \mathrm{N})$ are cross section at the planes as indicated in (K, M). Abbreviations: elaA, elastaseA; sst2, somatostatin 2; shh, sonic hedgehog; tf, transferrin. 


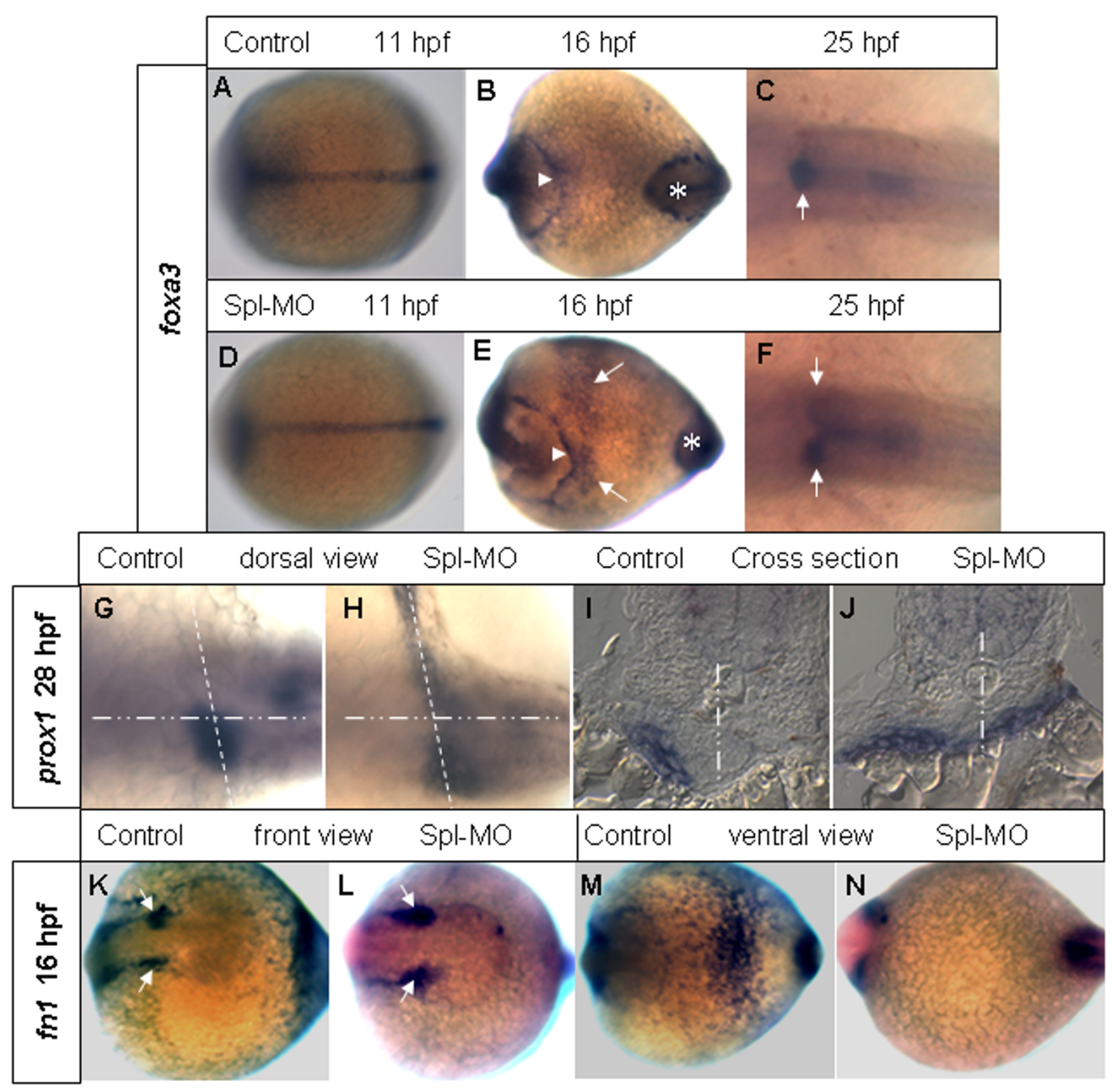

\section{Figure 5}

Rbp4 MO affects the early events of liver patterning prior to formation of liver bud. (A-F) foxa3 expression in both control (A-C) and rbp4 morphant (D-F) at II hpf (A, D), 16 hpf (B, E) and 25 hpf (C, F) respectively. In (B) and (E), triangles indicate the hatching gland and asterisks the tail bud. The arrows in (E) indicate the ectopic foxa3 expression in rbp4 morphant. The arrows in (C, F) indicate the liver buds. $(G, H)$ Dorsal view of prox I expression at 28 hpf in whole mount control $(G)$ and morphant $(H)$ embryos. (I, J) Cross section of the embryos as indicated by the dashed lines in $(G, H)$ respectively. The point/ dash lines represent midline of the embryos. (K-N), fnl expression at 16 hpf in control (K, M) and rbp4 morphant (L, N): front view $(K, L)$ and ventral view $(M, N)$. The arrows in $K$ and $L$ indicate the $f n l$ expression in anterior lateral plate mesoderm. 
sion pattern was noticed in Rbp4 morphants (data not shown). Thus, there is no evidence that a defect in endoderm or lateral plate mesoderm caused formation of the two liver buds in the morphants.

To examine the role of $r b p 4$ in hepatocyte migration, another early endoderm and hepatocyte marker prox 1 was used. The homeobox gene prox 1 is an early marker for the developing liver and pancreas of several vertebrates, including zebrafish, and plays a role in migration of hepatocytes during early liver development of mammals $[48,49]$. At $28 \mathrm{hpf}$, a small dot of prox 1 expression on the left side of the control embryo defined the liver bud, however, in morphants of the same stage, in addition to the prox 1 expression in the liver bud on the left side, a lineshaped prox 1 expression domain was found on the right side and it appeared to cross the midline to the left side (Figure 5G, H). Such morphological changes in appearance of endodermal cells have been interpreted as evidence of delayed migration of these cells [14]. In control embryos, the liver bud is located at the A-P level of somites 1-2. The line-shaped prox1 staining in morphants was found at the same A-P level. Cross-sections of morphants showed that the prox1-positive cells are indeed in the position of the liver bud just above the yolk, but the morphant liver bud is flatter (Figure 5I, J). Based on our current observations, it is likely that early hepatocyte precursor cells migrate into the liver bud and these cells are likely of endodermal origin as they expressed foxa3 and prox1 endoderm markers. The YSL expression of rbp4 appears to be necessary for the migration, which likely occurred from 16 hpf when rbp4 expression was largely increased (Fig. 1D) until 25-28 hpf when liver bud formation is completed (Fig. 5G).

Previously it has been reported that the YSL-specific transcription factor Mtx 1 regulates myocardial cell migration through downregulation of the extracellular matrix protein Fibronectin1 (Fn1) [14]. To investigate whether the $f n 1$ is involved in hepatocyte migration in the Rbp4 pathway, we examined $f n 1$ expression in Rbp4 morphants. As shown in Figure $5 \mathrm{~K}-\mathrm{N}, f n 1$ was downregulated in the ventro-lateral yolk where rbp4 is normally expressed. Interestingly, $f n 1$ expression in the myocardial precursor region was not affected in the Rbp4 morphants; consistent with this, no cardiac bifida was observed in the morphants. Thus $f n 1$ in the ventro-lateral yolk may be specifically involved in yolk extension formation and/or hepatocyte migration.

\section{Discussion}

Rbp4 is a plasma protein acting as a transporter of retinol in blood circulation. During early development $r b p 4$ is expressed in the YSL of zebrafish $[[18,50]$, this study]. Because of peculiarities of embryonic development in fish and mammals, direct comparison of the YSL to the extraembryonic structures in mammals is difficult, but comparison of expression of developmental genes may help to solve this puzzle. Rbp4 is expressed in the extra-embryonic endoderm of the yolk sac during embryonic development of the rat, mouse and chick [15-17]. Interestingly, zebrafish $r b p 4$ is expressed in the YSL on the surface of the yolk cell $[[18,50]$, this study], which, like the yolk sac in mammals, acts as a depot of maternal retinoids in zebrafish [4,5]. These observations suggest functional similarity of these extraembryonic structures in mammals and fish. Further, as suggested by Thomas et al. [51], the YSL plays an important role in early embryonic patterning similar to that of the anterior visceral endoderm (AVE) in mouse embryos [52]. Consistent with this, some murine genes homologous to Xenopus genes important in the organizer (e.g. hex, hesx1, lim1, otx2, cer-1, etc) are also expressed in the AVE [53]; interestingly, the zebrafish hhex is also expressed in the dorsal YSL in zebrafish during gastrula stage $[45,54]$.

Several early developmental genes, including $s q t$, cas and gata5, are expressed both in the YSL and adjacent vegetal blastomeres [55-58], but the specific roles of these genes in the YSL remain unknown since it is difficult to uncouple these functions from those in the marginal blastoderm. Now it is possible to target the YSL by injecting materials into the YSL only. It has been demonstrated that injections of RNAse into the YSL effectively eliminates YSL transcripts without affecting ubiquitously expressed genes in the blastoderm [13]. By this approach, important information about early function of YSL in the formation of ventro-lateral mesoderm and induction of Nodal-related genes in the ventro-lateral marginal blastomeres has been obtained [13].

However, the specific function of genes expressed in the late YSL remains largely unknown. While a number of genes are expressed in the YSL ubiquitously (e.g. $[38,59])$, zangptl2 is probably the only one with restricted posterior expression pattern in the YSL $[29,60]$. Our current work on zebrafish $r b p 4$ expression in the YSL provides another example illustrating patterning of the YSL. This non-uniform expression pattern suggests that at this stage the YSL could be patterned along the A-P and D-V axes. Consistent with this idea, the distinct morphogenetic domains in the YSL have been reported previously based on migration of its nuclei, though the underlying molecular mechanism remains unknown [61]. The restricted expression of $r b p 4$ in the YSL opens a question about mechanisms of such restriction, which we answered to some extent by demonstrating that the Nodal and Hh signalling pathways $[62,63]$ negatively control expression of $r b p 4$ similar to that of ceruloplasmin [28]. At the same time, RA seems to positively regulate expression of $r b p 4$ in the YSL. 
The effects of these signalling pathways on liver development require further experimental efforts. In our preliminary experiments, we noticed that both RA and DEAB led to no liver when the treatment was performed before but not after 16 hpf (data not shown). Although RA signalling could regulate rbp4 expression, it is difficult to conclude the involvement of Rbp4 in the RA signalling in regulation of liver development because of the pleitropic effect of RA. Nodal and Hh signalling pathways have been reported to play important roles in zebrafish endoderm development [64-71]. In our preliminary analyses using the Nodal and Hh mutants, most of them $\left(\mathrm{cyc}^{-/}, \mathrm{smu} \mathrm{H}^{-/}\right.$, $\mathrm{syu}^{-/}$, oep ${ }^{-/}$and $\left.\mathrm{cas}^{-/}\right)$showed either smaller or no liver (data not shown). Only sqt - - showed duplicated liver formation, which is probably due to its midline defect [72] as reported for another midline defect mutant $f l h \%$ [40]. However, liver bud duplication in Rbp4 morphant is unlikely due to the midline defect because the midline structure was remained normal in the Rbp4 morphant (Fig. 4G, H).

While it is widely accepted that the YSL plays a leading role during epiboly $[73,74]$, little information is available about the function of YSL after epiboly. It is not known whether the YSL at this stage influences the overlying cells just like that during early gastrulation or, alternatively, the embryo proper influences the patterning of the extraembryonic structures including the YSL. We discovered at least two different functions of Rbp4 within the YSL. First, Rbp4 deficiency results in abnormality of the YCE. Interestingly, rbp 4 starts to be expressed in the YSL a few hours before the formation of YCE. While the exact molecular mechanism behind the YCE formation is not known, it has been suggested that the YCE formation is influenced by the posterior to anterior migration of cells between the yolk and EVL. These cells accumulate at the level of YCE and could be responsible for YCE formation [29].

Second, Rbp4 is involved in the formation of the liver bud. As Rbp4 is not expressed in the endoderm during this process, its contribution is probably indirect through its role in the YSL. During organogenesis different cell lineages migrate to establish anlage of various organs and differentiate thereafter. Recently it has been reported that the YSL-specific factor Mtx1 plays a role in migration of myocardial precursor cells and posterior endoderm, as knockdown of Mtx 1 in the YSL results in cardia bifida due to a failure of myocardial cells to migrate to the midline. In parallel, 30\% of Mtx 1 morphants developed duplicated hepatic and pancreatic buds [14]. Moreover, duplication of liver bud has been also observed in other studies. Ober et al [75] have reported that Vegfc is required for coalescence of anterior endoderm to the midline and knockdown of Vegfc results in formation of a forked gut tube and duplicated buds of liver and pancreas. Similarly, Mat- sui et al [76] have also reported a new role of non-canonical Wnt signalling during migration of precursor cells toward the midline. The down-regulation of $\mathrm{Wnt} / \mathrm{Dvl} /$ RhoA signalling leads to the failure of fusion of the anterior gut tube and formation of duplicated livers and pancreas; in addition, migration of myocardial precursors toward the midline is also affected. In contrast to these observations, knockdown of Rbp4 has no effects on migration of heart precursors and the formation of the gut and pancreatic bud. Instead, the deficiency of Rbp4 causes a more limited effect resulting in formation of duplicated liver buds only. Consistent with this, we observed in the Rbp4 morphants that the cell migration molecule Fn 1 is specifically reduced in the ventro-lateral region of the yolk, where the rbp4 is normally expressed, but not in the myocardia progenitors; Meanwhile, the ectopic expression of foxa 3 appears specifically in the ventro-lateral region of the yolk. The ventro-lateral increase of foxa 3 and decrease of $f n 1$ suggested that the cells above the rbp4expressing YSL are probable hepatocyte progenitors which will migrate from the ventro-lateral yolk toward the midline depending on a Rbp4-Fn1 signalling pathway. Thus, the effect of Rbp4 is limited probably only to hepatocyte progenitors.

Recently, two conflicting hypotheses of organogenesis of zebrafish visceral organs have been proposed. One emphasizes the formation of the endodermal rod by migration of endodermal cells towards the midline and budding of all major endodermal organs from the rod ([26], reviewed in [25]) while the other puts more weight on the establishment of independent primordia of these organs and their later assembly [27]. Based on the data available, we suggest a unified theory of formation of endodermal organs; i.e. following the formation of the endodermal rod through convergence of the endodermal cells at the midline and the budding of organ primordia, there is continued cell migration from posterior to anterior and from lateral to medial, adding more cells to the buds of organs. Previously, based on analysis of expression pattern of ceruloplasmin in the wild type and mutant zebrafish, migration of liver progenitors from both sides of the yolk cell to the midline has been postulated during formation of the liver bud and a role of midline signaling in this process has been illustrated [28]. Migration of liver progenitors is probably a part of a more general process of migration of endodermal cells that contributes also to organogenesis of the pancreas, interrenal gland and heart $[14,29,41]$. Thus cell migration during the late phase of formation of visceral organs seems to be rather common in zebrafish. Similarly, it has been shown in mice by cell fate mapping that there are different groups of liver precursor cells which migrate to form the liver bud [24]. Our analysis of Rbp4 morphants demonstrated that on the surface of the yolk there are two spatially separated popu- 
lations of liver precursor cells found on both sides of the midline as proposed earlier [28]. It seems that these cells require an input from the YSL for proper migration. In the present study, we demonstrated that the YSL-expressed Rbp4 is necessary for migration of liver progenitors towards the midline and formation of a single liver bud.

Rbp4 is the extracellular transporter of retinol, a precursor of RA that has been implicated in regulation of cell migration as a stimulator and as an inhibitor of this process depending on the cellular context [77-79]. It stimulates neuronal migration in the zebrafish hindbrain [80]. In view of these earlier observations, our current data suggest that retinoids could play a role in regulating migration of early hepatic cells during the process of liver formation. Given the fact that during the course of our analysis we only evaluated molecular markers and morphology of the heart, pancreas and liver, retinoids could be involved in regulation of cell migration during formation of some other visceral organs that were not analysed here. The developmental roles of Rbp4 in zebrafish revealed in this study should also be considered within a much more general context of metabolism of retinoids in extraembryonic structures that seems to be evolutionarily conserved in all vertebrates studied so far([4,5], reviewed in $[81])$.

\section{Conclusion}

Rbp4 is traditionally considered to function as a retinol binding protein of the serum. Here we showed that during embryogenesis rbp4 mRNA was expressed only in the ventro-lateral YSL and later this expression expanded to cover the posterior YSL in early zebrafish embryos. rbp4 expression was negatively regulated by Nodal and Hh signalling and positively controlled by RA. This restricted expression pattern suggested that despite being a syncytium the YSL is patterned. Later $r b p 4$ was expressed in the liver. Knockdown of Rbp4 in the YSL resulted in shortened yolk extension as well as the formation of two liver buds, which could be due to impaired migration of liver precursor cells. In contrast, exocrine and endocrine pancreas, intestine and heart developed normally in Rbp4 morphants. Thus we suggest that $r b p 4$ expression in the YSL is required only for liver development.

\section{Methods \\ Fish maintenance}

Zebrafish were maintained in the fish facilities at the Department of Biological Sciences, National University of Singapore and the Institute of Molecular and Cell Biology in Singapore according to established protocols [82] and in compliance with Institutional Animal Care and Use Committee (IACUC) guidelines. Developmental stages were defined according to Kimmel et al [74] and presented in hours post fertilization (hpf) or days post fertilization (dpf).

\section{DNA sequencing and analysis}

The rbp4 cDNA clone (A10) was selected from our zebrafish EST collection [30] and sequenced completely. DNA sequencing reaction was performed using BigDye ${ }^{\mathrm{TM}}$ Terminator Cycle Sequencing Ready Reaction Kit (Perkin Elmer, USA) and products of the reaction were separated using the automated sequenator ABI 377 (Perkin Elmer, USA). Sequence analyses and protein identity comparison were performed using DNAMAN`software.

\section{RT-PCR}

Total RNA was isolated from embryos of selected stages and one-step RT-PCR reaction was conducted using the Qiagen OneStep RT-PCR Kit (Qiagen, Germany). The primers used for amplification of $r b p 4 \mathrm{cDNA}$ were 5'CAGAACGAGGTATCAAGGAA 3' as forward primer and 5'GTCCTCATCCAGCTCTCTGC 3' as reverse primer. The primers for testing the splicing Rbp4 morpholino were as follows: F1, 5'GAGAACGAGGTATCAAGGAAC 3'; F2, 5' GTAAGTCAACCAGTGTTTCC 3'; and R1, 5' CGCGTCTGTATTTGCCCAGG 3'.

\section{Whole mount in situ hybridization and sectioning}

Whole mount in situ hybridization using digoxigenin (DIG)-labeled riboprobes was carried out as previously described [83]. The plasmids were linearized with a restriction enzyme followed by in vitro transcription with a proper RNA polymerase for antisense RNA probes. Embryos were fixed with $4 \%$ paraformaldehyde (PFA), hybridized with the Dig-labeled RNA probe in hybridization buffer ( $50 \%$ formamide, 5XSSC, $50 \mu \mathrm{g} / \mathrm{ml}$ tRNA and $0.1 \%$ Tween 20 ) at $68^{\circ} \mathrm{C}$, followed by incubation with anti-Dig antibody conjugated with alkaline phosphatase (AP) and staining with the substrates, NBT (nitro blue tetrazolium) and BCIP (5-bromo, 4-chloro, 3-indolil phosphate).

Two-colour WISH was performed using a combination of the Dig- and fluorescein-labelled probes. For hybridization, two probes were added to the same tube and the embryos were incubated at $68^{\circ} \mathrm{C}$ overnight. After the first staining with AP-conjugated anti-Fluorescein antibody using Fast Red as substrate to obtain red staining, the embryos were incubated with $0.1 \mathrm{M}$ glycine $(\mathrm{pH} 2.2)$ at room temperature for 30 minutes to remove the phosphatase activity. Then the embryos were washed four times (10 minutes each) with PBST (phosphate-buffered saline with $0.1 \%$ Tween 20) and incubated in blocking buffer (5\% Blocking reagent in malic acid buffer; Roche, Germany) at room temperature for 1 hour. The second staining was performed using AP-conjugated anti-DIG antibody and the substrates, NBT and BCIP, to produce purple precipitates. 
For sectioning, the stained embryos were embedded in $1.5 \%$ Bactoagar- $5 \%$ sucrose and the block containing the embryo was trimmed in desired orientation. The block was then cryoprotected in $30 \%$ sucrose at $4{ }^{\circ} \mathrm{C}$ overnight, mounted into the cryo-mounting media, frozen in liquid nitrogen vapour and sectioned in the cryostat (Microm, Germany). 10-15 $\mu \mathrm{m}$ sections were fixed with $4 \%$ PFA in phosphate-buffered saline (PBS) for $10 \mathrm{~min}$, washed with PBS and mounted in 1:1 PBS:glycerol for observation.

\section{Nuclear Staining}

For nuclear staining $10-15 \mu \mathrm{m}$ sections were equilibrated briefly with phosphate buffered saline (PBS). Approximately $300 \mu \mathrm{L}$ of $300 \mathrm{nM}$ DAPI (4'6-diamidino-2-phenylindole-dihydrochloride) in PBS was applied to the section and incubated for 5 minutes. The sections were then rinsed several times in PBS and mounted in glycerol/ PBS (1:1), followed by observations under a fluorescence microscope (excitation $358 \mathrm{~nm}$, emission $461 \mathrm{~nm}$ ).

\section{Morpholino microinjection into YSL}

Three Rpb4 antisense norpholino oligonucletides were designed and used in the present study: ATG-MO, 5' GAGCCTTAACATACTGCCTCTGTGC 3'; Sp1-MO, 5' GTTGACTTACCCTCGTTCTGTTAAA 3' and Mis-MO,

5' GTTcACTTAgCgTCcTTCTCTTAAA 3' (the mismatch nucleic acids are in lower case) Microinjection of MO into YSL was performed at $4 \mathrm{hpf}$ stage. The embryos were mounted at proper orientation into pre-made 3\% agar wells with egg water $(0.3 \%$ sea salt, Red Sea brand). The tip of a microinjection pipette was positioned at the blastoderm margin area close to the junction of blastomeres and the yolk. $0.5-1.0 \mathrm{nl}$ of solution containing a defined dose of morpholino and fluorescent marker (Fluorescein or Texas Red labelled $70 \mathrm{kDa}$ dextran) was injected into wild type (AB strain) or Tg(ins: $g f p)$ embryos. Usually over $90 \%$ of injected embryos showed evenly distributed fluorescent dye in the YSL and these embryos were used for further analyses.

\section{Authors' contributions}

ZL performed all experiments, developed working hypotheses and wrote the manuscript. VK developed a concept of the project and wrote the manuscript. ZG initiated the project and finalized the manuscript. All authors have read and approved the manuscript.

\section{Acknowledgements}

We thank Dr. Svetlana Korzh for mutant embryos, Dr. Shuo Lin for $\mathrm{Tg}$ (ins:gfp) line, Ms. Lee-Thean Chu and Dr. Steven Fong for comments on the manuscript and colleagues in Z.G. and V.K. laboratories for fruitful discussions. proxl, gata6 and foxa3 constructs for making probes were provided by Mr. H. Huang and Dr. J. Peng at the IMCB. We are obliged to the personnel of the Fish Facilities of the DBS at NUS and IMCB for excellent technical support. This project was supported by grants from the Biomed- ical Research Council (BMRC) of Singapore. VK's lab in the IMCB was supported by the Agency for Science, Technology and Research of Singapore.

\section{References}

I. Kimmel CB, Law RD: Cell lineage of zebrafish blastomeres. II. Formation of the yolk syncytial layer. Dev Biol 1985, 108:86-93.

2. Kane DA, Kimmel CB: The zebrafish midblastula transition. Development 1993, II 9:447-456.

3. Donovan A, Brownlie A, Zhou Y, Shepard J, Pratt SJ, Moynihan J, Paw BH, Drejer A, Barut B, Zapata A, Law TC, Brugnara C, Lux SE, Pinkus GS, Pinkus JL, Kingsley PD, Palis J, Fleming MD, Andrews NC, Zon LI: Positional cloning of zebrafish ferroportin I identifies a conserved vertebrate iron exporter. Nature 2000, 403:776-78I.

4. Lampert JM, Holzschuh J, Hessel S, Driever W, Vogt K, von Lintig J: Provitamin A conversion to retinal via the beta, beta-carotene- I 5,15 '-oxygenase (bcox) is essential for pattern formation and differentiation during zebrafish embryogenesis. Development 2003, 130:2173-2186.

5. Isken A, Holzschuh J, Lampert JM, Fischer L, Oberhauser V, Palczewski K, von Lintig J: Sequestration of retinyl esters is essential for retinoid signaling in the zebrafish embryo. J Biol Chem 2007, 282:||44-||5|.

6. Trinkaus JP: The yolk syncytial layer of Fundulus: its origin and history and its significance for early embryogenesis. J Exp Zool 1993, 265:258-284.

7. Mizuno T, Shinya M, Takeda $\mathrm{H}$ : Cell and tissue transplantation in zebrafish embryos. Methods Mol Biol 1999, 127:15-28.

8. Mizuno T, Yamaha E, Kuroiwa A, Takeda $\mathrm{H}$ : Removal of vegetal yolk causes dorsal deficencies and impairs dorsal-inducing ability of the yolk cell in zebrafish. Mech Dev 1999, 8I(I2):5I-63.

9. Ober EA, Schulte-Merker S: Signals from the yolk cell induce mesoderm, neuroectoderm, the trunk organizer, and the notochord in zebrafish. Dev Biol 1999, 21 5:167-181.

10. Jesuthasan S, Stahle U: Dynamic microtubules and specification of the zebrafish embryonic axis. Curr Biol 1997, 7:3I-42.

1I. Fekany K, Yamanaka Y, Leung T, Sirotkin HI, Topczewski J, Gates MA, Hibi M, Renucci A, Stemple D, Radbill A, Schier AF, Driever W, Hirano T, Talbot WS, Solnica-Krezel L: The zebrafish bozozok locus encodes Dharma, a homeodomain protein essential for induction of gastrula organizer and dorsoanterior embryonic structures. Development 1999, I26:1427-I438.

12. Rodaway A, Takeda H, Koshida S, Broadbent J, Price B, Smith JC, Patient R, Holder N: Induction of the mesendoderm in the zebrafish germ ring by yolk cell-derived TGF-beta family signals and discrimination of mesoderm and endoderm by FGF. Development 1999, I26:3067-3078.

13. Chen S, Kimelman D: The role of the yolk syncytial layer in germ layer patterning in zebrafish. Development 2000, 1 27:468I-4689.

14. Sakaguchi T, Kikuchi Y, Kuroiwa A, Takeda H, Stainier DY: The yolk syncytial layer regulates myocardial migration by influencing extracellular matrix assembly in zebrafish. Development 2006, 133:4063-4072.

15. Soprano DR, Soprano KJ, Goodman DS: Retinol-binding protein and transthyretin mRNA levels in visceral yolk sac and liver during fetal development in the rat. Proc Natl Acad Sci USA I986, 83:7330-7334.

16. Johansson S, Gustafson AL, Donovan M, Romert A, Eriksson U, Dencker L: Retinoid binding proteins in mouse yolk sac and chorio-allantoic placentas. Anat Embryol (Berl) 1997, 195:483-490.

17. Barron M, McAllister D, Smith SM, Lough J: Expression of retinol binding protein and transthyretin during early embryogenesis. Dev Dyn 1998, 2 I 2:413-422.

18. Tingaud-Sequeira A, Forgue J, Andre M, Babin PJ: Epidermal transient down-regulation of retinol-binding protein 4 and mirror expression of apolipoprotein $\mathrm{Eb}$ and estrogen receptor 2a during zebrafish fin and scale development. Dev Dyn 2006, 235:307I-3079.

19. Duncan SA: Mechanisms controlling early development of the liver. Mech Dev 2003, 120:19-33.

20. Lemaigre $F$, Zaret KS: Liver development update: new embryo models, cell lineage control, and morphogenesis. Curr Opin Genet Dev 2004, 14:582-590. 
21. Zaret KS: Regulatory phases of early liver development: paradigms of organogenesis. Nat Rev Genet 2002, 3:499-5I2.

22. Warga RM, Nusslein-Volhard C: Origin and development of the zebrafish endoderm. Development 1999, | 26:827-838.

23. Chalmers AD, Slack JM: The Xenopus tadpole gut: fate maps and morphogenetic movements. Development 2000, 127:381-392.

24. Tremblay KD, Zaret KS: Distinct populations of endoderm cells converge to generate the embryonic liver bud and ventral foregut tissues. Dev Biol 2005, 280:87-99.

25. Ober EA, Field HA, Stainier DY: From endoderm formation to liver and pancreas development in zebrafish. Mech Dev 2003, 1 20:5-18.

26. Field HA, Ober EA, Roeser T, Stainier DY: Formation of the digestive system in zebrafish. I. Liver morphogenesis. Dev Biol 2003 253:279-290.

27. Wallace $\mathrm{KN}$, Pack $M$ : Unique and conserved aspects of gut development in zebrafish. Dev Biol 2003, 255:12-29.

28. Korzh S, Emelyanov A, Korzh V: Developmental analysis of ceruloplasmin gene and liver formation in zebrafish. Mech Dev 2001, 103:137-139.

29. Lyman Gingerich J, Lindeman R, Putiri E, Stolzmann K, Pelegri F: Analysis of axis induction mutant embryos reveals morphogenetic events associated with zebrafish yolk extension formation. Dev Dyn 2006, 235:2749-2760.

30. Gong Z, Yan T, Liao J, Lee SE, He J, Hew CL: Rapid identification and isolation of zebrafish cDNA clones. Gene 1997, 20 I:87-98.

31. Vogel AM, Gerster T: Expression of a zebrafish cathepsin L gene in anterior mesendoderm and hatching gland. Dev Genes Evol 1997, 206:477-479.

32. Itoh M, Kim C-H, Palardy G, Oda T, jiang Y-J, Maust D, Yeo S-Y, Lorick K, Wright GJ, Ariza-McNaughton L, Weissman AM, Lewis J, Chandrasekharappa $S C$, Chitnis $A B$ : Mind Bomb is a ubiquitin ligase that is essential for efficient activation of notch signaling by Delta. Dev Cell 2003, 4:67-82.

33. Blomhoff $\mathrm{R}$, Blomhoff HK: Overview of retinoid metabolism and function. INeurobiol 2006, 66:606-630.

34. Maden $M$ : The role of retinoic acid in embryonic and postembryonic development. Proc Nutr Soc 2000, 59:65-73.

35. Begemann G, Marx M, Mebus K, Meyer A, Bastmeyer M: Beyond the neckless phenotype: influence of reduced retinoic acid signaling on motor neuron development in the zebrafish hindbrain. Dev Biol 2004, 27 I: I 19-129.

36. Nasevicius A, Ekker SC: Effective targeted gene 'knockdown' in zebrafish. Nat Genet 2000, 26:216-220.

37. Heasman J: Morpholino oligos: making sense of antisense? Dev Biol 2002, 243:209-2I4.

38. Mudumana SP, Wan H, Singh M, Korzh V, Gong Z: Expression analyses of zebrafish transferrin, ifabp, and elastaseB mRNAs as differentiation markers for the three major endodermal organs: liver, intestine, and exocrine pancreas. Dev Dyn 2004, 230:165-173.

39. Bisgrove BW, Essner J], Yost HJ: Multiple pathways in the midline regulate concordant brain, heart and gut left-right asymmetry. Development 2000, I 27:3567-3579.

40. Liu YW, Gao W, Teh HL, Tan JH, Chan WK: ProxI is a novel coregulator of $F f I b$ and is involved in the embryonic development of the zebra fish interrenal primordium. Mol Cell Biol 2003, 23:7243-7255.

4I. Chai C, Liu YW, Chan WK: Fflb is required for the development of steroidogenic component of the zebrafish interrenal organ. Dev Biol 2003, 260:226-244.

42. Huang H, Vogel SS, Liu N, Melton DA, Lin S: Analysis of pancreatic development in living transgenic zebrafish embryos. Mol Cell Endocrinol 2001, 177:1 17-124.

43. Holtzinger A, Evans T: Gata4 regulates the formation of multiple organs. Development 2005, 132:4005-40|4.

44. Odenthal J, Nusslein-Volhard C: fork head domain genes in zebrafish. Dev Genes Evol 1998, 208:245-258.

45. Ho CY, Houart C, Wilson SW, Stainier DY: A role for the extraembryonic yolk syncytial layer in patterning the zebrafish embryo suggested by properties of the hex gene. Curr Biol 1999, 9:1131-1134.

46. Wallace KN, Yusuff S, Sonntag JM, Chin AJ, Pack M: Zebrafish hhex regulates liver development and digestive organ chirality. Genesis 200I, 30:14I-I43.
47. Patterson LJ, Gering M, Patient $\mathrm{R}: \mathbf{S c l}$ is required for dorsal aorta as well as blood formation in zebrafish embryos. Blood 2005, 105:3502-35II.

48. Sosa-Pineda B, Wigle JT, Oliver G: Hepatocyte migration during liver development requires ProxI. Nat Genet 2000, 25:254-255.

49. Burke Z, Oliver G: ProxI is an early specific marker for the developing liver and pancreas in the mammalian foregut endoderm. Mech Dev 2002, I I 8: I47-155.

50. Sumanas S, Jorniak T, Lin S: Identification of novel vascular endothelial-specific genes by the microarray analysis of the zebrafish cloche mutants. Blood 2005, 106:534-54I.

51. Thomas PQ, Brown A, Beddington RS: Hex: a homeobox gene revealing peri-implantation asymmetry in the mouse embryo and an early transient marker of endothelial cell precursors. Development 1998, I 25:85-94.

52. Beddington RS, Robertson EJ: Axis development and early asymmetry in mammals. Cell 1999, 96:195-209.

53. Sakaguchi $\mathrm{T}$, Mizuno $\mathrm{T}$, Takeda $\mathrm{H}$ : Formation and patterning roles of the yolk syncytial layer. In Pattern formation in zebrafish Edited by: Solnica-Krezel L. New york: Springer; 2002:12-14.

54. Liao W, Ho CY, Yan YL, Postlethwait J, Stainier DY: Hhex and scl function in parallel to regulate early endothelial and blood differentiation in zebrafish. Development 2000, 127:4303-43।3.

55. Dickmeis T, Mourrain P, Saint-Etienne L, Fischer N, Aanstad P, Clark $M$, Strahle U, Rosa F: A crucial component of the endoderm formation pathway, casanova, is encoded by a novel soxrelated gene. Genes Dev 200I, I5: 1487-I492.

56. Kikuchi Y, Agathon A, Alexander J, Thisse C, Waldron S, Yelon D, Thisse B, Stainier DY: casanova encodes a novel Sox-related protein necessary and sufficient for early endoderm formation in zebrafish. Genes Dev 200I, I 5:| 493-1505.

57. Reiter JF, Kikuchi Y, Stainier DY: Multiple roles for Gata5 in zebrafish endoderm formation. Development 2001, I 28: I25-135.

58. Sakaguchi T, Kuroiwa A, Takeda $\mathrm{H}$ : A novel sox gene, 226D7, acts downstream of Nodal signaling to specify endoderm precursors in zebrafish. Mech Dev 200I, 107:25-38.

59. Hirata T, Yamanaka Y, Ryu SL, Shimizu T, Yabe T, Hibi M, Hirano T: Novel mix-family homeobox genes in zebrafish and their differential regulation. Biochem Biophys Res Commun 2000, 271:603-609.

60. Kubota Y, Oike Y, Satoh S, Tabata Y, Niikura Y, Morisada T, Akao M, Urano T, Ito $Y$, Miyamoto T, Watanabe S, Suda T: Isolation and expression patterns of genes for three angiopoietin-like proteins, AngptlI, 2 and 6 in zebrafish. Gene Expr Patterns 2005 5:679-685.

61. D'Amico LA, Cooper MS: Morphogenetic domains in the yolk syncytial layer of axiating zebrafish embryos. Dev Dyn 200I, 222:6| I-624.

62. Müller F, Albert S, Blader P, Fischer N, Hallonet M, Strähle U: Direct action of the Nodal-related signal Cyclops in induction of sonic hedgehog in the ventral midline of the CNS. Development 2000, I27(18):3889-3897.

63. Rohr KB, Barth KA, Varga ZM, Wilson SW: The nodal pathway acts upstream of hedgehog signaling to specify ventral telencephalic identity. Neuron 200I, 29:34I-35I.

64. Schier AF, Neuhauss SC, Helde KA, Talbot WS, Driever W: The one-eyed pinhead gene functions in mesoderm and endoderm formation in zebrafish and interacts with no tail. Development 1997, 124:327-342.

65. Whitman M: Nodal signaling in early vertebrate embryos: themes and variations. Dev Cell 200I, I:605-617.

66. Aoki TO, David NB, Minchiotti G, Saint-Etienne L, Dickmeis T, Persico GM, Strahle U, Mourrain P, Rosa FM: Molecular integration of casanova in the Nodal signalling pathway controlling endoderm formation. Development 2002, 129:275-286.

67. Dougan ST, Warga RM, Kane DA, Schier AF, Talbot WS: The role of the zebrafish nodal-related genes squint and cyclops in patterning of mesendoderm. Development 2003, I30:|837-|85|

68. Ingham PW, McMahon AP: Hedgehog signaling in animal development: paradigms and principles. Genes Dev 200I, I 5:3059-3087.

69. Ramalho-Santos M, Melton DA, McMahon AP: Hedgehog signals regulate multiple aspects of gastrointestinal development. Development 2000, I 27:2763-2772. 
70. Lees C, Howie S, Sartor RB, Satsangi J: The hedgehog signalling pathway in the gastrointestinal tract: implications for development, homeostasis, and disease. Gastroenterology 2005, 129:1696-1710.

71. Hebrok M: Hedgehog signaling in pancreas development. Mech Dev 2003, I 20(I):45-57.

72. Feldman B, Gates MA, Egan ES, Dougan ST, Rennebeck G, Sirotkin HI, Schier AF, Talbot WS: Zebrafish organizer development and germ-layer formation require nodal-related signals. Nature 1998, 395: $181-185$.

73. Solnica-Krezel L, Driever W: Microtubule arrays of the zebrafish yolk cell: organization and function during epiboly. Development 1994, I 20:2443-2455.

74. Kimmel CB, Ballard WW, Kimmel SR, Ullmann B, Schilling TF: Stages of embryonic development of the zebrafish. Dev Dyn 1995, 203:253-310.

75. Ober EA, Olofsson B, Makinen T, Jin SW, Shoji W, Koh GY, Alitalo $\mathrm{K}$, Stainier DY: Vegfc is required for vascular development and endoderm morphogenesis in zebrafish. EMBO Rep 2004, 5:78-84.

76. Matsui T, Raya A, Kawakami Y, Callol-Massot C, Capdevila J, Rodriguez-Esteban C, Izpisua Belmonte JC: Noncanonical Wnt signaling regulates midline convergence of organ primordia during zebrafish development. Genes Dev 2005, 19:164-175.

77. Axel DI, Frigge A, Dittmann J, Runge H, Spyridopoulos I, Riessen R, Viebahn R, Karsch KR: All-trans retinoic acid regulates proliferation, migration, differentiation, and extracellular matrix turnover of human arterial smooth muscle cells. Cardiovasc Res 200I, 49(4):85I-62.

78. Joshi S, Guleria R, Pan J, DiPette D, Singh US: Retinoic acid receptors and tissue-transglutaminase mediate short-term effect of retinoic acid on migration and invasion of neuroblastoma SH-SY5Y cells. Oncogene 2006, 25(2):240-7.

79. Wang TW, Zhang $\mathrm{H}$, Parent JM: Retinoic acid regulates postnatal neurogenesis in the murine subventricular zone-olfactory bulb pathway. Development 2005, I32( I 2):272 I-32.

80. Linville A, Gumusaneli E, Chandraratna RA, Schilling TF: Independent roles for retinoic acid in segmentation and neuronal differentiation in the zebrafish hindbrain. Dev Biol 2004 270(I):186-199.

8I. Evans T: Regulation of hematopoiesis by retinoid signaling. Exp Hematol 2005, 33(9): 1055-6I.

82. Westerfield $M$ : The zebrafish book, a guide for the laboratory use of zebrafish (Danio rerio). 4th edition. University of Oregon Press, Eugene, OR; 2000.

83. Korzh V, Sleptsova I, Liao J, He J, Gong Z: Expression of zebrafish bHLH genes ngn $I$ and nrd defines distinct stages of neural differentiation. Dev Dyn 1998, 21 3:92-104.

Publish with Bio Med Central and every scientist can read your work free of charge

"BioMed Central will be the most significant development for disseminating the results of biomedical research in our lifetime. "

Sir Paul Nurse, Cancer Research UK

Your research papers will be:

- available free of charge to the entire biomedical community

- peer reviewed and published immediately upon acceptance

- cited in PubMed and archived on PubMed Central

- yours - you keep the copyright
BioMedcentral 